\title{
MUGNAI, NICCOLO; NIKOLAUS, JULIA; RAY, NICHOLAS. DE AFRICA ROMAQUE: MERGING CULTURES ACROSS NORTH AFRICA. LEICESTER: THE SOCIETY FOR LIBYAN STUDIES, 2016.
}

Luiz Alberto das Neves Marchiori ${ }^{1}$

\section{Palavras-chave}

Romanização; África do Norte; Niccolo Mugnai; Julia Nikolaus; Nicholas Ray.

Esta resenha pretende refletir sobre a dominação romana no norte da África durante o período do império, bem como procura entender a maneira como os grupos sociais existentes reagiram ao invasor. Para tanto, resenharei $D e$ Africa Romaque: Merging Cultures Across North Africa, uma vez que esta obra traz à tona o debate sobre as formas pouco estudadas da interação romana com os povos locais, revisitado nos últimos anos por diversos pesquisadores da área.

A obra De Africa Romaque, organizada por Niccolo Mugnai, Julia Nikolaus e Nicholas Ray, a partir do que podemos observar, nasceu baseando-se nas perspectivas atuais do conceito de romanização, segundo as quais, embora houvesse diversas sociedades bem organizadas, pouca pesquisa foi realizada sobre a sobrevivência das culturas locais.

Sobre esta questão, os pesquisadores têm se dedicado de forma mais profunda, colocando em pauta varias problemáticas, tais como se as tradições locais sobreviveram, como e por que estas tradições foram alteradas ou revividas sob o domínio romano, além de traçar o papel desempenhado pelos legados pré-romanos neste processo de longa duração e entender as necessidades locais em termos de arquitetura, planejamento urbano, arte, economia e agricultura.

Para levar a cabo este intento, Mugnai organizou o livro com uma introdução geral e mais cinco capítulos temáticos, e, por fim, uma conclusão. Dentro destas temáticas o autor fez subdivisões de 3 a 5 artigos, de 18 autores diferentes. Cada autor escreve um texto e, ao fim, cita todas suas referencias bibliográficas, que facilitam o entendimento do capitulo e criam, por assim dizer, ferramenta de pesquisa para outros pesquisadores, bem como fornecem meios para comprovação dos seus próprios argumentos.

\footnotetext{
${ }^{1}$ Mestrando - Universidade Federal de São Paulo, São Paulo, Brasil. E-mail: luiz.alberto. marchiori@gmail.com
} 
O Norte de África antes de Roma: tradições indígenas e seu legado é o que guia e intitula o primeiro capitulo. Dentro deste capitulo existem três artigos que procuram lançar luz sobre as contribuições dos povos locais no desenvolvimento das sociedades norte-africanas, mais tarde encontradas por Roma.

O primeiro artigo questiona as concepções de textos clássicos, que foram reforçadas na era colonial, nas quais os "indígenas" africanos eram receptores passivos das tradições dos colonos, sejam eles neste caso fenícios, gregos ou mesmo romanos, e traz com isso novas informações para uma reavaliação. $\mathrm{O}$ autor ainda salienta que devido às primeiras cidades terem se tornado cidades romanas de sucesso, devido à arquitetura monumental e pisos de mosaico, desencoraja-se sondagens mais profundas no solo.

O segundo artigo traz uma visão das evidencias sobre as rotas de comércio entre os assentamentos localizados no Saara Oriental em direção ao Vale do Nilo bem como em direção ao Mediterrâneo no final da Idade de Bronze. Há uma revisão entre as viagens de longa distancia e os caminhos que eram, ou não, utilizados para estas viagens. Este texto traz consigo as descobertas dos últimos anos, que devem conduzir pesquisadores a investigarem as conexões da África Subsaariana até a Costa do Mediterrâneo.

Já o terceiro artigo deste capitulo nos traz informações sobre a análise de trezentos túmulos funerários do primeiro milênio a.C, bem como o debate sobre a formação de um proto estado no norte da África. O artigo propõe ainda um modelo de estudo evidenciando uma chave para compreender a complexidade da sociedade emergente da África do Norte neste período.

Planejamento, desenvolvimento e transformação na paisagem urbana no Norte da África é o tema do segundo capitulo. Sua estrutura também formada por três artigos que reúnem informações sobre a mudança arquitetônica e urbana das cidades. Através disso demonstra a influencia dos povos locais durante o período helenístico, romano e Antiguidade Tardia.

O primeiro artigo deste capítulo traz as pesquisas sobre o Opus Quadratum e o Opus Africanum discutindo as técnicas construtivas da arquitetura do Norte da África entre o segundo século a.C. e o inicio do período Imperial. Este artigo procura entender como as tradições, tanto helenísticas quanto romanas influenciaram seus antecessores, como, por exemplo, os fenícios.

Já o segundo artigo trata do estudo do layout e organização urbanística da cidade de Dionisias, uma cidade helenística na província de Fayum. O autor estuda esta cidade grega com plano ortogonal mostrando que a cidade contem tradições egípcias e, com isso, mostra a influência nativa sobre a cultura do colonizador. 
O último artigo deste capitulo nos informa sobre as áreas residenciais e públicas em Cirene na Antiguidade Tardia. Este estudo de caso avalia a evolução e transformação entre o período imperial e a Antiguidade Tardia mostrando a mudança de espaços públicos para espaços residenciais utilizando, como analise, a Ágora e o Ginásio entre o período da segunda metade do século III d.C. e o sétimo século.

O capitulo terceiro deste livro, intitulado Percepção e Representação do Poder, Identidades Étnicas e Culturais, explora as percepções que podemos extrair dos textos antigos e outras fontes, além de tratar sobre como o norte da África foi entendido pelos romanos e a interação entre esses e os berberes, abordando, também, na posteridade, a identidade crista e não-cristã com o legado romano.

O primeiro artigo deste capítulo trata das evidencias literárias e arqueológicas, principalmente a distribuição de moedas e a cerâmica para visualizar as questões do imperialismo romano no Norte da África, em Cartago, entre 146 a.C. e 46 d.C.

O segundo artigo aborda a apresentação do triunfo de Cornelio Balbus em 19 a.C., através do texto de Plínio, o Velho, buscando, assim, entender a compreensão geográfica romana, mostrando que havia uma confusão em torno da apresentação das regiões e dos povos conquistados, mas que a maioria pretendia apenas demonstrar a importância e imensidão da conquista romana.

O ultimo artigo deste capitulo trata da identidade religiosa e étnica em Tipasa na Antiguidade Tardia, através de estudos das biografias dos santos.

O quarto capítulo. intitulado Economias do Norte da África: produção, tecnologia e comércio, abordará a importância das produções locais e como estas são minimizadas, sendo apresentada tão somente a importância da produção com a presença do colonizador romano.

O primeiro artigo deste capítulo irá tratar sobre a produção de azeite em Dionisias e nos mostrar as mudanças tecnologicas após a conquista romana, conforme nos apontam as novas pesquisas arqueológicas. Desta análise se retira a existência de uma cultura material pertencente à tradição egípcia e uma continuidade com novos dispositivos importados pelos romanos.

O segundo artigo deste capítulo analisa as oficinas de ânforas de Zitha, na Tripolitania tunisiana, e a partir da produção, identificar estes tipos de ânforas em todo o mediterrâneo.

O terceiro artigo irá tratar dos materiais de construção importados para o norte da África, entre eles o tijolo e a pedra, bem como o papel das cargas de 
retorno como lastros de navio. A partir desses materiais destinados à construção e edificações em geral, entender a necessidade destes para criação de edifícios no estilo romano e buscar o reflexo com a capital.

O ultimo capitulo deste livro se intitula criando uma impressão duradoura: Motivos arquitetônicos e decorativos, e irá tratar da continuidade da identidade da população local percebida na arte e na arquitetura, bem como, também, da influência mútua e os romanos a população local.

O primeiro artigo deste capítulo trata da apresentação do individuo na analise dos cemitérios de Cirene, entendendo assim a prática funerária que tem uma grande mudança na representação de bustos ou figuras de deusas funerárias. O exame destes bustos nos mostra que mesmo nos retratos que trazem um modo romano de celebrar os mortos há uma influencia que perdura de uma pratica funerária regional centenária.

Já o segundo artigo foca seus esforços nas variações arquitetônicas e decorações esculpidas em pedra, buscando analisar os estilos decorativos, principalmente as representações da agricultura. Com essa analise, a autora nos mostra que havia uma separação muito clara entre a elite local e o povo, devido ao local que foi colocado o mausoléu. Primordialmente, pode-se ver que os laços com as culturas ancestrais continuam existindo pelo estilo e preferência adotados.

O terceiro artigo deste capítulo nos informa sobre a decoração arquitetônica de Sala e os legados púnicos e helenísticos na Mauritânia Tingitana Romana. $\mathrm{O}$ artigo apresenta os resultados de uma pesquisa de campo feita em Sala e nos traz informações da continuidade dos legados pré-romanos em elementos arquitetônicos, como cornijas egípcias e capitéis jônicos gregos. $\mathrm{O}$ autor ainda aponta a mistura de arte oficial ou mesmo criações de elementos arquitetônicos que não encontram paralelo fora de Tingitana.

O quarto artigo deste capitulo traz informações sobre a retomada de tradições helenísticas tanto na arquitetura como na decoração após o século III d.C., com o enfraquecimento de Roma, trazendo um levantamento documental de análise de diversos capitéis de todo Norte da África.

O ultimo artigo deste livro procura entender quais são as funções e uso destas estatuas imperiais no contexto urbano, que já haviam sido modificadas, além de analisar a relação entre culto ao imperador e a modificação dos espaços públicos durante o século IV d.C.

A conclusão do livro nos mostra que durante muito tempo o processo de romanização privilegiou estudos pensados pela lógica imperialista, e que este 
livro traz em si novos rumos de pesquisa para que se possam aprofundar novos conhecimentos sobre o Norte da África.

Meu intento em trazer esta resenha é, também, aprofundar o interesse do leitor em relação aos estudos do Norte da África. Segundo R. Bruce Hitchner, "Se existe um tema abrangente comum a todos os trabalhos, é sua disposição em desafiar a sabedoria convencional (...) O norte da África não estava isolado; sua história evidencia que as culturas do Mediterrâneo e do Oriente Médio se uniram ao nativo para produzir um espaço cultural distinto, multifacetado e complexo, um padrão histórico de engajamento que permanece intacto até hoje." ( Hitchner, 2016: 254). 